\title{
Olof Bäckersten
}

\section{Isaiah's Political Message}

\section{An Appraisal of His Alleged Social Critique}

[Jesajas politische Botschaft. Eine Untersuchung seiner angeblichen Sozialkritik.]

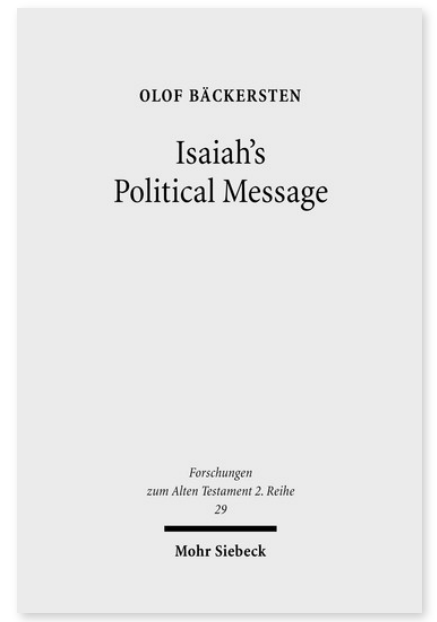

2008. VIII, 231 Seiten. FAT II 29

ISBN 978-3-16-151127-1

DOI 10.1628/978-3-16-151127-1

eBook PDF $74,00 €$

ISBN 978-3-16-149637-0

fadengeheftete Broschur 74,00€
Veröffentlicht auf Englisch.

Olof Bäckersten hinterfragt den wissenschaftlichen Konsens über eine sozialkritische Ausrichtung von Jesaja 1-39. Diese kommt beispielsweise in Textpassagen zum Ausdruck, in denen die Jersualemer Elite wegen ihrer selbstgefälligen Art, ihrem dekadenten Lebensstil und ihrer mehr oder weniger systematischen Unterdrückung der Armen verurteilt wird. Bäckersten argumentiert, daß die Textpassagen, die als Beweise dafür vorgebracht werden, sich statt dessen mit wenigen Ausnahmen auf Jesajas Widerstand gegenüber Judas Außenpolitik beziehen (und nicht auf soziale Ungerechtigkeit). Mit seiner Untersuchung macht er einen neuen Interpretaionsvorschlag und erklärt, wie und warum ein sozialkritischer Standpunkt mit dem außenpolitischen Diskurs im Buch Jesaja als ganzem in Verbindung steht.

Olof Bäckersten Born 1967; studied Theology at Lund University and the University of Gothenburg; post-graduate studies at Lund University; 2008 PhD; presently teaching biblical studies at the University of Gothenburg.

\section{Jetzt bestellen:}

https://mohrsiebeck.com/buch/isaiahs-political-message-9783161511271?no_cache=1

order@mohrsiebeck.com

Telefon: $+49(0) 7071-923-17$

Telefax: $+49(0) 7071-51104$ 